An Exploratory Model of Family Resilience Processes \& Functioning: A Cultural Perspective of the Semai Indigenous Communities in Perak, Malaysia 


\begin{abstract}
Given the challenges experienced by the Semai indigenous communities in Perak, Malaysia and their distinct cultural beliefs, it is important to understand the role of the social and cultural networks in their resilience processes. In particular, further attention needs to be paid to how their families function and shape their beliefs about their lives, as there might be key mechanisms and processes that differ from existing general conceptualizations of family. This grounded theory analysis of 23 Semai Orang Asli (indigenous) community members established a model of the Semai's family conceptualization and functioning. Findings revealed that the Semai's concept of family encompasses an extensive network of individuals with their shared relationship with nyenang (spirit ancestors) and cultural heritage, which in turn leads them to have a deep sense of shared family identity and connectedness. This worldview guided the Semai's family processes and functioning, captured by the following five dimensions: sharing obligations and responsibilities, making collective decisions, prioritizing community's welfare, sharing of knowledge and resources and willingness to work with everyone. These factors facilitate a conducive and supportive environment aimed at maintaining existing family relationships. This model can guide the development of culturally specific programmes that promote and strengthen indigenous family relationships and resilience.
\end{abstract}

Keywords: Family Processes and Functioning, Indigenous Family Model, Indigenous culture, Peninsular Malaysia, Semai, Southeast Asia 


\section{An Exploratory Model of Family Resilience Processes \& Functioning: A Cultural Perspective of the Semai Indigenous Communities in Perak, Malaysia}

Unlike the general population, minorities and indigenous communities are subjected to a diverse range of challenges due to their unique socio-political situations. These challenges include cultural suppression, discrimination, eviction from their ancestral lands and the violation of their human rights (e.g., Erni, 2015; Friborg, Sørlie, \& Hansen, 2017; IWGIA, 2016). These circumstances have threatened their cultures, languages and livelihoods, forcing them to undergo radical changes and reconfigurations to their beliefs and worldviews (Kirmayer, Sehdev, Whitley, Dandeneau, \& Isaac, 2009). As such, their beliefs, values and social practices may differ from the general population, prompting for the need to investigate how their unique culture and cultural beliefs influence their psychological processes. Additionally, the exposure to these challenges may have profound impacts on their general health (Wong, Allotey, \& Reidepath, 2018), mental health and well-being (Friborg et al., 2017; Wallace, Nazroo, \& Bécares, 2016).

The Semai are a sub-ethnic indigenous community (Orang Asli in the Malay language) that reside in the northern central regions of Peninsular Malaysia (Gomes, 2016; Nicholas, 2000). They are the largest sub-ethnic group who comprise about $28 \%$ of the entire Orang Asli population (Endicott, 2016). Some of the adversities experienced by the Semai today can be attributed and traced back to the history of colonization and oppression (Edo, 1998; Masron, Masami, \& Ismail, 2013). During the pre-colonial period, the Semai and their Orang Asli counterparts were perceived to be primitive savages (Idrus, 2011). They were viewed as the greatest local source of slaves and were treated with cruelty and injustice. When the Portuguese and Dutch colonized Melaka, this old practice continued. It was not until the arrival of the British that active measures were taken to phase out slavery and to protect the Orang Asli (Idrus, 2011). 
During the British administration, specific laws (e.g., Aboriginal Peoples Act 1954) were drafted to protect the Orang Asli. However, post-independence, the motive switched from protection to advancement - where the Orang Asli were viewed as a group who requires assimilation and integration into the general society (Idrus, 2011). Revisions were made to the Aboriginal Peoples Act in 1974 to provide the department powers to control the Orang Asli by creating and regulating Orang Asli settlements, controlling entry into Orang Asli settlements as well as the crops they grow and the use of their lands (Nicholas, 2000), subsequently undermining the Orang Asli's local autonomy over their traditional lands. The effects of such policies continue to impact the Orang Asli today where they continue to be culturally suppressed, and marginalized through deliberate governmental actions and colonial policies. Some of these include forced displacement, degradation of the natural environment surrounding their communities, and cultural discontinuity due to the dispossession of their cultural and ceremonial practices (e.g., Edo, 1998; Gomes, 2016; Nicholas, 2000). Yet, Semai communities have long survived the multiple adversities to their mental and physical well-being, demonstrating high levels of resilience - the ability of a dynamic system to endure and overcome significant challenges (Kirmayer et al., 2009; Masten, 2011).

Over the years, there has been an increase in the number of studies examining resilience processes and mechanisms that facilitate communities' positive adaptation under challenging circumstances. Studies have identified that people draw strength from their social and cultural networks such as their families to overcome challenges (e.g., Burnette et al., 2019; MacPhee, Lunkenheimer, \& Riggs, 2015; Prendergast \& MacPhee, 2017). These dynamics, interactions and interrelationships were at the heart of weaving a strong and unique fabric of resilience as families act as a foundation of social and emotional support in times of adversities (Burnette et al., 2019; MacPhee et al., 2015). Acknowledging the importance of the role of family in studying resilience, further investigation on how one's 
cultural ideals and context influence the complex interactions that occur within these networks is required. The distinct cultural values and beliefs held by minority and indigenous communities may provide unique interpretations of family structure and functioning that help them survive the challenges they face as marginalized groups.

Previous studies of̣ indigenous peoples have indeed recognized family relationships and functioning as an important factor in shaping resilience (e.g., Carriere, 2007; Chua, Kadirvelu, Yasin, Choudhry, \& Park, 2019; Friborg et al., 2017; Kirmayer et al., 2009). For example, First Nations children who were separated from their family, community and culture were found to be more prone to the adverse effects such as emotional instability rising from negotiated indigenous identity as compared to their counterparts who were not separated from their families (Carriere, 2007). Meanwhile, Chua et al.'s (2019) systematic review of indigenous communities demonstrated that the communities who emphasized social cohesion tended to overcome challenging situations by sharing responsibilities, making collective decisions and showing openness to collaborate (Chua et al., 2019). While the existing literature helps identify the factors that promote resilience for indigenous communities, there is a lack of knowledge on the meaning of family for indigenous communities and how this may have an impact on their resilience. Therefore, this study aims to examine how indigenous communities like the Semai community conceptualizes family and how thoseey families function to nurture resilience.

\section{Family Processes and Functioning}

Families are perceived to be the building blocks of healthy functioning communities, as they serve as the primary source for the formation of attitudes, behaviors, beliefs and values (Kirmayer et al., 2009; Ogwo, 2013). They provide a conducive environment for children to grow into healthy adults and act as support systems for its members (Ungar, 2004). During crises and adversities, families engage in several processes to respond to the 
challenges experienced. Families would assist members to make meaning of the challenges experienced and subsequently facilitate a hopeful and positive outlook, enabling the family system to come together to overcome stress, reduce risks of dysfunction and support optimal adaptation (Walsh, 2012), which are vital for nurturing resilience. These processes may vary across different socio- cultural and historical contexts, for they often shape perceptions on the importance of the family, level of commitment to the family, and the degree of dependence on the family for emotional support and decision-making (Park, 2015).

As the ways on how family operates and is understood may vary across cultures and contexts, it is essential to examine them within specific contexts. Traditionally, one may conceptualize the family as "the biological relationship of parents to a child along with the marital or union status of parents" (Manning, Brown, \& Stykes, 2014, p. 1). However, the concept of family in other cultures and contexts is predicated on more than just biological factors, or relationships between parents and children. To illustrate, family for many indigenous communities comprised of their extended relations which include multiple generations and all members of their extended family, living and dead (Bang, Nolan, \& McDaid-Morgan, 2018; Theron \& Theron, 2013). The different ways in which the family is conceptualized highlight the complexity of defining families and how it operates across cultures. This has prompted for further investigation using the emic approach.

The emic approach examines a phenomenon from the accounts of individuals in particular cultural contexts (Helfrich, 1999). This approach assumes that the phenomenon under study may not be similar in all cultural groups. For instance, indigenous family structures in South Africa consist of all members of extended family, living and dead (Theron \& Theron, 2013), while traditional family structures of aboriginal communities in Australia revolved around kinship systems where the composition of their households tend to be complex and fluid with adults and children often moving between different households $(\mathrm{Qu}$ 
\& Weston, 2013). The different conceptualizations of family, even within indigenous communities, suggest the need to clarify the definition of a 'typical' family using the emic approach especially in an area which is relatively under-explored. It would also provide local and specific cultural interpretation of the concept of family and how it functions, which cannot be explained by generalized models and theories.

\section{The Current Study}

In sum, the literature points to the importance of examining the concept of family and its functioning within specific contexts and cultures. Given the hardships that the Semai indigenous community in Southeast Asia have been faced with, the way they interpret their family and its functioning would provide a better understanding of how they develop and maintain resilience. Furthermore, existing models of family functioning may not be able to accurately explain the processes by which the Semai family operate. Thus, further studies on family functioning would be needed given its role in influencing the physical, social and emotional well-being of a community (Bang et al., 2018). As the concept of family and its functions are diverse in its composition and forms, it is worthy to examine the concept of family and how they influence the lived experience of the community under study. With these goals, this study aimed to utilize the grounded theory approach to build upon these models and subsequently establish a model of the Semai's concept of family and how they function. Specifically, this model will explain the meanings and the structure of family for Semai indigenous communities.

\section{Methods}

Strauss and Corbin's (1998) grounded theory was used to develop a model to explain the meaning or structure of the Semai family and how it functions. This approach was deemed the most appropriate as pre-existing theories of family and its functioning may not accurately account for the Semai family (Strauss \& Corbin, 1998). Additionally, grounded 
theory would allow for an emic perspective of Semai community by defining their concepts of family and its functioning. As such, data collection and analysis for this study were guided by grounded theory (Corbin \& Strauss, 2008; Strauss \& Corbin, 1998). The research objectives were used to point to an area of inquiry. Subsequently, the emergent data was used to develop an explanatory theory elucidating the construct of the Semai family and its functioning free from the restrictions of a preconceived model.

In this study, focus group interviews were conducted to examine the Semai concept of family and functioning that were not yet in the literature. Focus group discussions (FGD) allowed the researchers to gain access to the participants' shared views, experiences and attitudes (Morgan, Krueger, \& King, 1998). Additionally, the social context of the focus group would assist the participants in making meaning of their past and current life experiences (Hollander, 2004). In this sense, participants were able to develop insights from what the other participants shared and make meaning out of their own experience (Karasz \& Singelis, 2009). Furthermore, conversations on the positive and negative emotional events could create shared meaning. This is particularly relevant for the Semai indigenous peoples who culturally viewed themselves as part of the collective, providing shared stories about their families and how they function. Six FGDs in total were conducted in this study, with each group compriseding of aboutfour, two, threefour, five, five and three to five interviewees respectively.

\section{Researcher's Positionality}

The first author is a trained qualitative non-indigenous researcher who has worked with the Orang Asli community for the past ten years. Additionally, the author is a human rights advocate and trainer who has worked with Jaringan Kampung Orang Asli Semenanjung Malaysia (JKOASM), a village network of the Orang Asli in Peninsular Malaysia with 30,000 Orang Asli members living in the states of Perak, Pahang, Selangor, 
Negeri Sembilan, Malacca, Johor and Kelantan in Peninsular Malaysia. To this extent, the first author's experience in working with the indigenous peoples provided the research team the knowledge of the local dynamics and culture of the Orang Asli community. This was helpful in enhancing the validity of the analysis as the first author was able to provide full information about the life circumstances of the participants (Morrow, 2005). As such, the data collection was conducted by the first author in an unbiased manner-with respect and appreciation for the Semai's local cultural beliefs and practices. Additionally, the other authors are non-indigenous academics/researchers with the expertise in the health and psychology research and with good knowledge of qualitative methods. All authors worked in Malaysia when the research was conducted, had previous experience with cultural or indigenous research and approached the data with cultural sensitivity.

\section{Participants}

Participants were initially recruited using purposive sampling, where experiences of the most appropriate individuals who fulfil the criteria of the research question were explored. The participants were required to be 18 years old and above, able to communicate in the Malay language, belong to a Semai community, reside in the Perak state and currently practicing practice the Semai tradition and religion. As the theory began to emerge, additional participants were recruited using theoretical sampling, a technique used to recruit participants who can provide additional views on emerging concepts (Corbin \& Strauss, 2008; Strauss \& Corbin, 1998). Additionally, this technique was used to improve the sample diversity. Most early participants recruited were senior male village elders, leaders and community members; therefore, the recruitment strategy was adjusted to include more women and younger Semai community members. Theoretical saturation was reached when new participants presented similar responses which fits the existing codes. 
The final sample consisted of 16 men and 7 women $(N=23)$ who are members of the Semai indigenous community, able to communicate in the Malay language, reside at the Perak state and are currently practiceing the Semai tradition and religion. The participants' age ranged from 26 to 72 years old $(M=48.48, S D=14.62)$. They represented a wide range of positions in the village: tok penghulu (village leader), tok hala' (shamans), village elders, and community members. Additionally, the participants were recruited from six Semai villages, Kampung. Tisong, Kampung. Senta, Kampung. Sat, Kampung. Kjau, Kampung. Sandin and Kampung. Gedong which are located at the fringes between Bidor and Sungkai town in the southern region of the Perak state.

\section{Data collection and analysis}

Following Monash University Human Research Ethics Committee (MUHREC) ethics approval (Project Number: 11397), the researchers approached a representative from JKOASM, a local village network of Peninsular Malaysia indigenous peoples, who has worked closely with the Semai community in the Perak state for decades. The representative acted as the gatekeeper community liaison in contacting the potential participants and arranging the logistics of the study. Discussions were conducted with the gatekeeper community liaison to inform them about the research process and to obtain the gatekeeper's community liaison's mutuatagreement to ensure the quality of the data collected. Two community leaders accompanied the researcher to the interviews, and one acted as the SemaiMalay language translator.

All FGD were conducted in the Malay language. Prior to the start of the FGD, all participants were informed about the purpose of the research both verbally and in writing in both Malay and their native Semai language. Subsequently, they were informed that their responses would remain confidential and anonymous, and that they were free to withdraw from the study at any point of time without any consequences. All participants provided 
informed consent. The FGD were guided by an interview schedule (refer to Appendix A) framed in an open-ended manner to ensure flexibility (Corbin \& Strauss, 2008). Subsequent questions were developed based on the ongoing analysis and emerging data, guided by the emerging theory (Corbin \& Strauss, 2008; Strauss \& Corbin, 1998). The direction of later questions, driven by the emerging theory, included a small number of probing questions to delve into the participants' construal of the family and family processes (Corbin \& Strauss, 2008; Strauss \& Corbin, 1998). The FGD ranged in duration from 61 to 101 minutes, were audio recorded and transcribed verbatim. As the FGD were conducted in the Malay language, the transcripts were translated by the researcher to English and were shared with a bilingual expert to verify the translation. Monetary award was given to the village upon completion of the FGD.

In grounded theory, the process of data collection and analysis are intertwined and repetitive (Strauss \& Corbin, 1998). Data analysis occurred throughout the entire research process. As it would be impossible to transcribe and code each FGD before proceeding to the next interview due to busy interviewing periods, the process of data collection and analysis were done concurrently. The researcher listened to the audio recording of the FGD and made notes about important concepts that emerged. Additionally, the initial interviews showed that the women and younger Semai community members provided unique inputs (e.g., there are no gender or age division in the community's work). Therefore, the researcher decided to make amendments to the recruitment strategy by including more women and younger Semai community members in the subsequent FGDs to ensure theoretical saturation. The 'formal analysis' took place upon completion of all FGDs and when the transcripts were translated from Malay to English. All transcripts were read one or multiple times in order to obtain a sense of the overall context of the data. 
Open coding, in which was conducted where concepts were identified within the text, was conducted. Those concepts were collapsed and developed into categories to represent what the researchers thought would be themes or important elements in a theory about the Semai's family functioning (Corbin \& Strauss, 2008; Strauss \& Corbin, 1998). Additionally, theoretical memos were generated to explain the researchers' thoughts on what family means to the Semai. Subsequently, axial coding was conducted where connections between detailed codes were identified and refined to provide clearer explanations on the Semai's concept of family and functioning (Corbin \& Strauss, 2008). At the following phase of data analysis, the researchers engaged in theory elaboration by examining the flaws in the logic and cases that support or challenge their conclusions. This process was completed with all researchers to ensure triangulation. To illustrate the data analysis process, initial codes such as connection to nyenang, sharing similar language and coming from the same region were identified as factors that constitute the Semai's family. Additionally, factors such as sharing of knowledge and resources and prioritizing community's interest were identified as the ways on how the Semai family functions. The data analysis process was conducted by the first, second and fourth authors. After each author has completed his/her data analysis, the themes were compared. When the interpretations differed, discussions were conducted between the researchers until the most suitable interpretation was found to ensure that the meanings and characteristics of the Semai family and its functioning are reflective of the participants' description. The final model and the themes were agreed upon by all authors. Additionally, regular meetings and analytical sessions were held throughout the entire analysis process to ensure data credibility.

\section{Results and discussion}

The findings obtained from the data collection and analysis indicated that the Semai community held unique interpretations of the concept of family. The Semai understood the 
family to include not only those with blood relations but also their community members and individuals with shared relationship with nyenang (spirit ancestors in the Semai language) and cultural heritage. Their concept of family guided their family processes and the numerous ways on how they interacted and functioned. These processes helped create a conducive and harmonious environment as the basis for the resilient community. Figure 1 illustrates a representation of the emergent concepts and depicts their interrelationships in the form of a grounded theory model.

\section{Semai Family Structure}

The Semai viewed family holistically where in which every individual in the community with shared relationship with nyenang and cultural heritage is considered to be a family member. The Semai perceived their relationship with nyenang to be central to their lives. It acted as a key element that connects every Semai individual together. The Semai believed that they originate from the same root:

"The Semai Orang Asli share the same ancestors. Our ancestors gave birth to a few children and it continues until the generations after that. Therefore, we consider everyone, the Semai Orang Asli here as siblings.” (Akmal, 57, male)

"My ancestors come from the same person. After that, their children get married elsewhere. They will spread the family. It becomes bigger. The new generation will continue to spread." (Robin, 38, male)

They were able to identify familial relationships by tracing their linkages through their family history and background. Participants shared that often, the stories of their origins were transmitted across generations through oral tradition and storytelling, which served to inform them about how their identity and generations are intertwined:

"When I meet another person whom I do not know, I may feel that we are not related. But when the elders come, they will ask you questions... because they may know who 
your elders are, so they will ask you, who is your mother, your father. If they are not familiar, they will probe further... who is your grandmother? Your grandmother from the maternal side, your grandfather from the maternal side. After you explain, the elder will regard you as a family." (Tamrin, 72, male)

"How do we know they are family? First, the stories. Their parents will tell them, in the past, their grandfather's children (were) married here. So, when the grandfather's children had grandchildren or children, when we meet them, we will start asking them, who are your parents? If we do not know they are, we will go home and ask our elders to find out who that person is then only we know that person is our relative." (Abu, 44, male)

In addition to their relationship with nyenang, family membership was based on sharing of cultural heritage (traditional behavior and way of life), as well as the common language spoken and connection to the land and environment:

"(What) determined them as family members are them living here for long periods of time. They understand the way we interact (and way of life) like looking for petai or searching for forest products. They know their whereabouts and they do the same things we do." (Kamsiah, 40, female)

"We do not call the Temiar or Jakun (other sub-ethnic groups) uncle or tok (grandfather) even though they are from the same ethnic group. If they (come from the same sub-ethnic group and speaks the same language), we will refer them as grandfather, grandmother, brother. That is what we call as family." (Raimi, 25, male) "As long as that person is a Semai Orang Asli, we would regard them as our own people. Even though we do not know where he/she comes from, we will call him/her maihi. Maihi refers to our people in the Semai language." (Raju, 48, male) 
Additionally, the Semai family was constructed on flexible relationship terms where they can have multiple mothers, fathers, uncles, aunties, brothers and sisters regardless of blood relations:

"In this village, everyone is regarded as my grandchildren. I do not treat them like outsiders. Even though if it is another person's child, I would still regard them as my grandchildren. Anyone else too because they are all our family. " (Tamrin, 72, male) "In considering them (other community members) as family, we regard other family members as uncles, aunties, grandchildren. (...) Even though we are not brothers from the same father and mother, we would regard each other as brothers. " (Raimi, 25 , male)

It is important to emphasize that the Semai's relationship with nyenang and cultural heritage were essential features that shaped the Semai's family identity. Contrary to generalized conceptualization of family where family was defined based on the biological relationships (Manning et al., 2014), the Semai’s family was defined based on specific relationship rules and not genetic closeness. In this sense, it can be suggested that the Semai adopted the classificatory system of kinship based on abstract relationship rules and genealogical relations (Trautmann, 2001). This kinship system formed a sense of shared family identity and provided a deep sense of belonging and connectedness among other Semai people and communities. The Semai's concept of family guided-informed their key family processes and functioning by determining their obligations, responsibilities and appropriate behaviors to maintain and uphold their kinship relations (see Figure 1). This has led them to value the principle of reciprocity, viewing themselves to be interwoven to one another and emphasize collectivity which is vital in ensuring effective family functioning. 


\section{Family functioning}

The Semai's family processes and functioning were defined based on their concept of family. As familial connections and relationships were pivotal in the lives of the Semai, the ways they operate and function were guided by the principal of reciprocity. In this grounded theory model, the Semai's family processes were demonstrated in the following five interrelated dimensions of functioning that formed the core of how the Semai understood and felt supported by their families - sharing obligations and responsibilities, making collective decisions, prioritizing community's welfare, sharing of knowledge and resources and willingness to work with everyone.

Sharing obligations and responsibilities. The Semai acknowledged that every family member had an obligation and responsibility to one another. In this sense, responsibilities were distributed among the large family network. They would look after one another and ensure that they participated in every communal event. Additionally, they would offer their assistance and contribute wherever required:

"Whenever there is a problem, we will gather together. They will ensure that at least half of their household will be present there. If there isn't half, at least representatives, two to three persons from one house will come. They will join the discussion and will inform what was discussed to their family members at home." (Robin, 47, male)

"We will discuss as a family whenever there are problems or matters pertaining the village. We will assist one another. Whenever there is a problem like encroachment in another village, I will go and help the other village. That means we are united. Today, if someone encroach my land, the villagers from the other village will come and help me out. It is like this." (Rubiah, 60, female) 
Social and caring responsibilities such as the upbringing of the child were also distributed among the entire family network. Child rearing was not the sole responsibility of the biological parents but the entire extended family who may step in to provide emotional support and protection:

"If the child's parents are not around, if we do not help, then who else will? We have to help them. On the days when I am not around, in return, they (the child's parents) will help my child the same way." (Mia, 35, female)

“(Child rearing) is everyone's responsibility. In terms of food, their behavior, I will monitor them. If they do the things that they should not do, I will reprimand them." (Ramli, 62, male)

The distribution of obligations and responsibilities among the family members were also not discriminatory in nature. Age, gender or rank did not play any role in fulfilling the obligation. The participants explained:

"There is no difference in the workload (for the man and woman). For us, if it is a heavy workload it is the same. Light also the same." (Julia, 20, female)

"Like the paddy fields, there is no difference. Our entire family will go there. Whether it is the woman or the man. We will help each other. There is no difference." (Pairin, 25, male)

The Semai's sharing of obligations and responsibilities socialized them to be respectfully proactive to provide practical and emotional support whenever needed. This, in a sense, created a strong sense of dependability and interdependence among members of the family, strengthening their family relationships.

Making decisions collectively. The Semai emphasized the importance of equality and autonomy of all family members. Family members were free and open to express their ideas and opinions. Additionally, problems were recognized and communicated openly to everyone 
and the views of every family members were solicited before a decision was made. Even though discussions may be difficult and time consuming, decisions will be made collectively to avoid disunity:

"Everyone participates in decision making. They will evaluate the different suggestions. They will ask everyone (who were present there) one by one. Is the decision good? Why do we think it is good? Why do we accept it? Everyone, will be asked to provide their opinions on the decision. If it is good, we will accept it. In the end, they will accept the decision that is made and they will go by the decision." (Tamnrin, 72, male)

The Semai family valued the importance of negotiation and accepting differences demonstrating respect for their fellow community members. Collective decisions were made in a fair and egalitarian manner in the families:

"We do not make (decisions) based on ranks. We want our subordinates to make the decisions themselves. We will evaluate the suggestions (together). If we can use the idea, then we will. As the penghulu (village leader), I will bring (the decision) wherever I go." (Samsiah, 58, female)

"It is not the penghulu's (mandate) to make the sole decision. We do not rely on the penghulu only. We will conduct a discussion. We want to make a collective decision with the youths, women and elders." (Ramli, 62, male)

As the decisions were made in a collective manner, family members would feel reassured that their feedbacks were acknowledged and valued. It would also render problem solving to be more comprehensible and manageable, fostering their willingness to accept and support the decisions made:

"(After the discussion) the tasks will be divided. If we are having a wedding feast, we will decide who will buy the rice, the chicken or the fish and how many of us will go... 
How many will stay at home and wait to cut the chicken. They will do it voluntarily." (Ruslan, 28, male)

"If the roads are messy, we will have a meeting with everyone. We will discuss and identify who is interested to clean up this part. They will inform their area of preference and we will (collectively) clean up the place." (Arau, 36, male)

The Semai family's decision-making processes created a climate of mutual trust where every family member was encouraged to freely express their own emotions and opinions without being judged or shamed. This created a shared sense of comfort and security which strengthens internal solidarity and unity within the family.

Prioritizing community welfare. The Semai's decisions and actions were often made to safeguard the interest of the entire community (non-blood related family members with shared relationship with nyenang and cultural heritage), present and the future. They believed that their current decisions and actions would implicate their future generations. As such, the Semai felt a special sense of responsibility to ensure the survival of the community; hence, making decisions from a collectivistic viewpoint:

"We evaluate all suggestions given to us. Like in the future, would the decision be beneficial for everyone or only for two or three people. If it benefits only two to three people, we will not accept their suggestion." (Robin, 47, male)

"We will ask all community members whether they agree with the suggestion. They will consider whether (the suggestions) it is good for everyone in the future or not. If everyone believes the suggestion to be beneficial for all, we will accept the suggestion.” (Kamsiah, 40, female)

The Semai had a sense of obligation to continue and maintain the connections within the family. At the heart of the family, one's obligation to the family and community were 
regarded to be more important than material gain. This would ensure the continuity of the Semai family, creating a sense of security and assurance among family members.

Sharing of knowledge and resources. The Semai actively reported supporting family members who were experiencing hardships by sharing their available knowledge and resources. They were willing to share their limited resources in order to ease the burden experienced by family members who needed it. The participants shared:

"(When my child is sick...) I would definitely want to visit him/her. But if there is no money, my siblings or relatives will help out. They will say let's rotate. Today you can rest because you have already visited; so, we will rotate." (Nia, 50, female) "Any problems, the villagers will help whenever (possible). If we need money, we will collect. Collect money and pass it to those in need. If there is food, we will share. We need to help them out if there is a problem." (Rustam, 44, male)

Additionally, the knowledge and the stories shared assisted family members to adjust well to difficulties. The information shared would provide them with alternative views and ideas to approach an issue. This could help facilitate the development of creative methods to solve the issues experienced. The participant described:

"When (the villagers from) Kg. Chang come here, we will share our stories and problems experienced. (...) We could get new ideas from their sharing. For example, when they return from Kuala Lumpur (capital of Malaysia) or wherever, they will share their experiences. We will be able to learn how it is like there. If we have time to spare, we will go there and experience it." (Arau, 36, male)

The sharing of knowledge and resources was highly valued and promoted in the Semai family. It is seen as an obligation, especially if there is someone in need. In this sense, the sharing of one's wisdom and resources would benefit the family. The support provided would 
provide courage and hope to fellow family members that the challenges experienced can be overcome collectively.

Willingness to work with everyone. The Semai were willing to spend their time, chores and errands together with their family members. They valued the company of their family members and would create opportunities for any interested members to collectively participate in their daily activities. The participants described:

"Whenever there is a matter, we will meet up and discuss. We will call other villagers to join us. We will meet other community leaders or other people from different villages or nearby villages. We will meet at a middle ground, for example, the hall in Kg. Chang (to discuss).” (Tamnrin, 72, male)

"Whenever I go to the field... I can invite other children... They can join me. Just like that. It is not hard. (...) If I go to another village, I can ask also ask the family to join me. It is not that difficult. That is how the (Semai) Orang Aslis are." (Nia, 50, female) The Semai's willingness to work with everyone was not restricted to those from their own village only. Extended family members from other villages would also be invited to participate in community discussions whenever possible:

“(Whenever we have discussions), we will have discussions with other villages. We will discuss and make our decisions together. If we want to make a report, we will make a report with the penghulu and the committee members from other villages... They will join us to make a police report."(Ruslan, 28, male)

As a whole, the Semai's key family processes and functioning-were oriented to form a conducive and supportive environment aimed to strengthen and maintain existing family relationships which is vital in ensuring effective family functioning- Guided by their concept of family, the Semai's processes and mechanisms reinforced their Semai identity and ensured cohesion and social control. These actions helped develop a shared support system which 
allowed families to harness strengths and resources to survive and thrive. Families with strong support systems and networks were able to offer a rich, protective sense of belonging and cohesion (Black \& Lobo, 2008). Additionally, the extended relationships and social networks embedded in the Semai's conceptualization of family allowed the Semai to interact reciprocally with one another to provide assistance, avenues, services and resources essential for the welfare and the positive development of the community (Luthar, Cicchetti, \& Becker, 2000).

\section{Theoretical and Empirical Implications}

The current study has demonstrated that the Semai held different worldviews of family from the general population, suggesting that culture does indeed influence perceptions of family. Our findings reaffirmed the importance of the Semai's cultural view of indigenous spirituality in shaping family their beliefs and processes (Chua, Kadirvelu, Yasin, \& Park, 2020). Like other indigenous communities, the value of interconnectedness was prominent in the Semai's culture where this worldview guided them to view themselves as extensions of their family, community and ancestors (Chua et al., 2019). Additionally, the findings supported the need to examine specific psychological phenomenon from an emic approach (Helfrich, 1999). The Semai's unique interpretation of family take into account the totality of their ancestry and cultural characteristics. As indicated in the findings, the Semai's family were determined based on their relationship with nyenang and cultural heritage. These factors allowed them to identify members of their family and to build their understanding of family in the broad sense and how it affected them.

$\underline{\text { The Semai's cultural worldviews also influence and organize their family processes }}$ and responses to adversities. Contrary to how conventional families foster resilience by tapping into their family belief systems (making meaning of adversity, positive outlook, $\underline{\text { transcendence and spirituality), organization patterns (flexibility, connectedness and social }}$ 
and economic resources) and communication processes (clarity, open emotional expression and collaborative problem-solving) (Walsh, 2003), the Semai would engage in the following family processes - sharing obligations and responsibilities, making collective decisions, prioritizing community's welfare, sharing of knowledge and resources and willingness to work with everyone. In this sense, the ways how the Semai family foster healing and growth out of adversities were influenced by their cultural worldview.

The current findings, however, share some commonalities with existing theories of family processes and functioning such as the McMaster Model of Family Functioning and the Process Model of Family Functioning (Miller, Ryan, Keitner, Bishop, \& Epstein, 2000; Skinner, Steinhauer, \& Sitarenios, 2000). Similar to both theories, our model sheds a light on the processes on how family functions effectively (Miller et al., 2000; Skinner et al., 2000). More specifically, our theory provided an overview of the factors that constitute the ways on how the Semai family functions to facilitate resilience. Our findings also suggest that the emphasis placed by existing theories of family processes and functioning varied across theories. For example, the McMaster Model of Family Functioning focused on providing appropriate environmental conditions for family members to grow (Miller et al., 2000) while the Process Model of Family Functioning focused on task accomplishments (Skinner et al., 2000). Rather than focusing on the conventional ways on viewing how family functions effectively, our findings focused-revealed on-how family functions to facilitate resilience. Additionally, it presented addressed the nuances of and the influences of culture and culturally transmitted values and beliefs. In this sense, the Semai placed a great emphasis on strengthening and maintaining existing and harmonious family relationships.

Several methodological strengths could be recognized in this grounded theory study. One of the major strengths of this study was the type of participants interviewed. The participants examined in this study encompassed a wide range of Semai individuals who 
varied in their gender, age, experience and position in the community. The wide variety of individuals that participated in this study had enriched the grounded theory model developed in this study. Furthermore, to the best of our knowledge, this is the first known study to provide a unique Semai specific theoretical conceptualization of family conceptualization and functioning.

\section{Limitations, Practical Implications and Conclusion}

Notwithstanding the strengths of the current study, several limitations were also noted in the current study. First, the participants interviewed in this study were predominantly from the Perak state. Apart from the Perak state, the Semai also reside at the Pahang state (Nicholas, 2000). As the indigenous communities are quite diverse, these results therefore may not be applicable to the Semai communities living in the Pahang state. Future studies should attempt to examine and test the applicability of the grounded theory with the Semai communities in the Pahang state. Although the present grounded theory model does not allow extensive generalizations, it would be interesting to examine if it could be applied in the other Orang Asli sub-ethnic groups or it might only be restricted to the Semai indigenous communities in Peninsular Malaysia. Another limitation identified was the use of English in the coding process. As the coding was not done in the original language of the interview, Malay, the narrative of interview may not be captured accurately (Twinn, 1997). Therefore, the coding process for future studies could be conducted in the original language of the interview to ensure accuracy.

Several practical implications could be deduced from the current grounded theory model. Although our findings demonstrate the collective nature of community, initiatives such as the preservation and promotion of traditional and cultural practices could be conducted to strengthen the relationship between members of the community. First, the documentation of the collective history and the intergenerational relationships of the Semai 
family would be helpful in maintaining their family identity and culture. The recorded information would act as an important educational tool to explain the Semai's complex family conceptualization and relationships to future generations and the general public. Additionally, regular activities at the community level such as sports events and communal activities that include all members of the Semai community such as the elders, men, women and the children would help bring people aroundtogether. Given the participation of all members of the community, such activities could facilitate sharing and cooperation across generations (Kirmayer et al., 2009). Such efforts would be beneficial in strengthening familial relationships which would be beneficial in enhancing resilience.

Additionally, much effort is needed to accommodate the indigenous culture in the government education system. The current Malaysian education system adopted a one-size fits all education system (Renganathan, 2016), which forces the Semai community to accommodate and assimilate into the mainstream culture which prioritizes individual achievements rather than the community. Such policies may not be helpful for the Semai community in maintaining their unique indigenous culture and beliefs which places great importance on familial relationships. Hence, accommodating the Semai's indigenous culture in the government education system by recognizing and acknowledging the strengths of their indigenous families and culture could assist them in preserving their unique culture and traditions, and subsequently strengthen their families and community resilience. 


\section{References}

Bang, M., Nolan, C. M., \& McDaid-Morgan, N. (2018). Indigenous family engagement: strong families, strong nations. In E. A. McKinley \& L. T. Smith (Eds.), Handbook of Indigenous Education. Singapore: Springer.

Black, K., \& Lobo, M. (2008). A conceptual review of family resilience factors. J Fam Nurs, 14(1), 33-55. doi: 10.1177/1074840707312237

Burnette, C. E., Boel-Studt, S., Renner, L. M., Figley, C. R., Theall, K. P., Miller Scarnato, J., \& Billiot, S. (2019). The Family Resilience Inventory: A Culturally Grounded Measure of Current and Family-of-Origin Protective Processes in Native American Families. Family Process. doi: 10.1111/famp.12423

Carriere, J. (2007). Promising practice for maintaining identities in First Nation adoption. First Peoples Child and Family Review, 3(1), 46-64.

Chua, R. Y., Kadirvelu, A., Yasin, S., Choudhry, F. R., \& Park, M. S. (2019). The cultural, family and community factors for resilience in southeast asian indigenous communities: A systematic review. Journal of Community Psychology, 1-22. doi: https://doi.org/10.1002/jcop.22224

Chua, R. Y., Kadirvelu, A., Yasin, S., Choudhry, F. R., \& Park, M. S. (2020). Indigenous spirituality as an integral resilience factor for Semai indigenous communities in Malaysia. Manuscript submitted for publication.

Corbin, J., \& Strauss, A. (2008). Basics of qualitative research: techniques and procedures for developing grounded theory (3rd ed.). Thousand Oaks: Sage Publications, Inc.

Edo, J. (1998). Claiming our ancestors' land: An ethnohistorical study of Seng-oi land rights in Perak, Malaysia. (Doctor of Philosophy). Australian National University, Canberra, Australia. 
Endicott, K. (2016). Malaysia's original people: Past, present and future of the Orang Asli. Singapore: NUS Press.

Erni, C. (2015). Shifting cultivation, livelihood and food security: New and old challenges for indigenous peoples in Asia. In C. Erni (Ed.), Shifting cultivation, livelihood and food security: New and old challenges for indigenous peoples in Asia. Bangkok: Asia Indigenous Peoples Pact.

Friborg, O., Sørlie, T., \& Hansen, K. L. (2017). Resilience to discrimination among indigenous Sami and non-Sami populations in Norway: The SAMINOR2 study. Journal of Cross-Cultural Psychology, 48(7), 1009-1027. doi:

$10.1177 / 0022022117719159$

Gomes, A. G. (2016). Semai ecological epistemologies: Lessons for a sustainable future. In K. Endicott (Ed.), Malaysia's original people: Past, present and future of the orang asli. Singapore: NUS Press.

Helfrich, H. (1999). Beyond the dilemma of cross-cultural psychology: Resolving the tension between etic and emic approaches. Culture \& Psychology, 5(2), 131-153. doi: $10.1177 / 1354067 \times 9952002$

Hollander, J. (2004). The social contexts of focus groups. Journal of Contemporary Ethnography, 33, 602-637. doi: 10.1177/0891241604266988

Idrus, R. (2011). The discource of protection and the Orang Asli in Malaysia. Kajian Malaysia, 29(1), 53-75.

IWGIA. (2016). The indigenous world 2016. Copenhagen, Denmark: International Work Group for Indigenous Affairs.

Karasz, A., \& Singelis, T. M. (2009). Qualitative and mixed methods research in crosscultural psychology. Journal of Cross-Cultural Psychology, 40(6), 909-916. doi: $10.1177 / 0022022109349172$ 
Kirmayer, L. J., Sehdev, M., Whitley, R., Dandeneau, S. F., \& Isaac, C. (2009). Community resilience: Models, metaphors and measures. Journal of Aboriginal Health, 5(1), 62117.

Luthar, S. S., Cicchetti, D., \& Becker, B. (2000). The construct of resilience. A critical evaluation and guidelines for future work. Child Development, 71(3), 534-568.

MacPhee, D., Lunkenheimer, E., \& Riggs, N. (2015). Resilience as regulation of developmental and family processes. Family Relations, 64(1), 153-175. doi: https://doi.org/10.1111/fare.12100

Manning, W. D., Brown, S. L., \& Stykes, J. B. (2014). Family complexity among children in the United States. The Annals of the American Academy of Political and Social Science, 654(6), 48-65. doi: 10.1177/0002716214524515

Masron, T., Masami, F., \& Ismail, N. (2013). Orang Asli in Peninsular malaysia: Population, spatial distribution and socio-economic condition. Journal of Ritsumeikan Social Sciences and Humanities 6, 75-115.

Masten, A. S. (2011). Resilience in children threatened by extreme adversity: Frameworks for research, practice, and translational synergy. Development and Psychopathology, 23, 493-506. doi: 10.1017/S0954579411000198

Miller, I. W., Ryan, C. E., Keitner, G. I., Bishop, D. S., \& Epstein, N. B. (2000). The McMaster approach to families: theory, assessment, treatment and research. Journal of Family Therapy, 22, 168-189.

Morgan, D. L., Krueger, R. A., \& King, J. A. (1998). The focus group kits. Thousand Oaks, CA: Sage.

Morrow, S. L. (2005). Quality and trustworthiness in qualitative research in counseling psychology. Journal of Counseling Psychology, 52(2), 250-260. doi: 10.1037/0022$\underline{0167.52 .2 .250}$ 
Nicholas, C. (2000). The Orang Asli and the contest for resources: Indigenous politics, development and identity in Peninsular Malaysia. Copenhagen, Denmark: International Work Group for Indigenous Affairs.

Ogwo, A. (2013). Adolescents-parent relationships as perceived by younger and older adolescents. IFE PsychologIA, 21(3), 222-227.

Park, M. S. (2015). Changing family perceptions across cultures: The Malaysian context. In S. Haque \& E. Sheppard (Eds.), Culture and cognition: A collection of critical essays (pp. 197-210). London, England: Peter Lang.

Prendergast, S., \& MacPhee, D. (2017). Family resilience amid stigma and discriminatinon: A conceptual model for families headed by sam-sex parents. Family Relations, 67(1), 26-40. doi: https://doi.org/10.1111/fare.12296

Qu, L., \& Weston, R. (2013). Australian households and families. Melbourne: Australian Insitute of Family Studies.

Renganathan, S. (2016). Educating the Orang Asli children: exploring indigenous children's practices and experiences in schools. The Journal of Educational Research, 109(3), 275-285. doi: 10.1080/00220671.2014.945150

Skinner, H., Steinhauer, P., \& Sitarenios, G. (2000). Family assessment measure (FAM) and process model of family functioning. Journal of Family Therapy, 2000, 190-210.

Strauss, A., \& Corbin, J. (1998). Basics of qualitative research: Grounded theory procedures and techniques (2nd ed.). London: Sage.

Theron, L. C., \& Theron, A. (2013). Positive adjustment to poverty: How family communities encourage resilience in traditional African contexts. Culture \& Psychology, 19(3), 391-413. doi: 10.1177/1354067X13489318

Trautmann, T. R. (2001). The whole history of kinship terminology in three chapters. Anthropological Theory, 1(3), 268-287. doi: 10.1177/14634990122228728 
Twinn, S. (1997). An exploratory study examining the influence of translation on the validity and reliability of qualitative data in nursing research. Journal of Advanced Nursing, 6(2), 418-423. doi: 10.1046/j.1365-2648.1997.1997026418.x.

Ungar, M. (2004). The importance of parents and other caregivers to the resilience of highrisk adolescents. Family Process, 43(1), 23-41. doi: 10.1111/j.15455300.2004.04301004.x

Wallace, S., Nazroo, J., \& Bécares, L. (2016). Cumulative effect of racial discrimination on the mental health of ethnic minorities in the United Kingdom. American Journal of Public Health, 106, 1294-1300.

Walsh, F. (2003). Family resilience: a framework for clinical practice. Family Process, 42(1), 1-18. doi: 10.1111/famp.2003.42.issue-1

Walsh, F. (2012). Family resilience: strengths forge through adversity. In F. Walsh (Ed.), Normal Family Processes (pp. 399-427). New York: Guillford Press.

Wong, Y. S., Allotey, P., \& Reidepath, D. D. (2018). Why we run when the doctor comes: Orang Asli responses to health systems in transition in Malaysia. Critical Public Health, 29(2), 192-204. doi: https://doi.org/10.1080/09581596.2018.1438588 
